\title{
Social norms and public transport usage: empirical study from Shanghai
}

\section{$\operatorname{AUTHOR}(\mathrm{S}):$}

Zhang, Dong; Schmöcker, Jan Dirk; Fujii, Satoshi; Yang, Xiaoguang

\section{CITATION:}

Zhang, Dong ...[et al]. Social norms and public transport usage: empirical study from Shanghai. Transportation 2016, 43: 869-888

\section{ISSUE DATE:}

2016-09

URL:

http://hdl.handle.net/2433/252362

\section{RIGHT:}

This is a post-peer-review, pre-copyedit version of an article published in Transportation. The final authenticated version is available online at: http://dx.doi.org/10.1007/s11116-015-9625-y.; この論文は出版社版でありません。引用の 際には出版社版をご確認ご利用ください。; This is not the published version. Please cite only the published version. 
1

This is the unformatted version of: Dong, Z., Schmöcker, J.-D., Fujii, S. and Yang, X. (2015). Social norms and public transport usage: Empirical study from Shanghai. Transportation. Available from: DOI 10.1007/s11116-015-9625-y

\title{
Social norms and public transport usage:
}

\section{Empirical study from Shanghai}

\author{
Dong Zhang ${ }^{\mathrm{a}}$, Jan-Dirk Schmöcker ${ }^{* \mathrm{~b}}$, Satoshi Fujii ${ }^{\mathrm{b}}$, Xiaoguang Yang ${ }^{\mathrm{a}}$

\begin{abstract}
a School of Traffic and Transportation Engineering, Tongji University, Room 502, Shanghai,
\end{abstract} \\ 201804, P.R.China
bDepartment of Urban Management, Kyoto University, C1-2-432, Nishikyo-ku, Kyoto 615-8540, Japan

\begin{abstract}
Chinese cities need to consider various TDM measures to cure adverse influences from exceeding private car ownership and use. We therefore explore the potential role of norms and awareness of problems caused by excessive car traffic for car purchase and mode choice decisions. With a sample of 465 responses collected via an online survey in Shanghai, our study suggests that the perception of "everyone around me is using public transport" (descriptive norms) is negatively correlated with car ownership. More importantly, we find that expectation of important others (subjective social norms) and internalized responsibility to use greener transport (personal norms activated by social problem awareness) stimulate the intention to use public transport and increase actual public transport usage. We further find that income does not influence public transport usage intentions or the actual modal choice directly but only via car ownership as mediating factor. We discuss that our findings support regulations to limit private car ownership and use but also to utilize "soft policy measures" in order to achieve a voluntary shift towards more sustainable travel behavior in Shanghai.
\end{abstract}

\section{Keywords}

Public transport usage; Car Ownership; Norms; Social problem awareness; China

\section{Introduction}

To encourage public transportation usage and to abate the conflict between mobility needs and the well-documented negative effects of exceeding private car usage, Shanghai has conducted measures both at the supply and the demand ends. Since 1993 a metro system is in operation 
which until 2012 has extended to $468 \mathrm{~km}$ with 13 lines and 289 stations. From 2001 to 2010, investments into the metro system have been averaging about USD1.7 billion per year (Peng et al, 2012). In 2010 alone, Shanghai municipal government spent 630 million USDon surface transit (Wu, 2011). Car ownership and usage reduction measures are conducted at the same time. Shanghai was the first Chinese city to adopt a policy of limiting overall car ownership by using a bid-auction mechanism for local vehicle registration as early as 1994. The lowest knock down price in April 2014 has exceeded USD1,1000, according to an announcement from the officially assigned auction corporation (The Shanghai International Commodity Auction Co., Ltd, 2014), even higher than prices of some Chinese brand private cars. Vehicles without local plate are prohibited to enter the downtown area during peak hours. At the same time, the monthly parking costs in Shanghai's CBD and other sub-centers averaged about USD300 in 2011, ranking 47 out of the top 50 cities worldwide, according to a report by Colliers International (2011).

Despite these measures being declared a great success (Shanghai Municipal Transport and Port Authority, 2013) implementation of further policies that encourage public transportation usage in Shanghai (and other Chinese cities) are required given the continuous growth in car ownership and usage. It appears that these "hard" measures, including improving public transport (PT) through infrastructure construction as well as car ownership and usage pricing policies, are not sufficient (Stopher,2004). Instead one might have to look "deeper" at individuals' motivations to use cars and public transport. Arguably the changing perception of the car not any longer as status symbol but as a polluter has been one reason for recent "peak car" developments and the success of soft transport policy measures in some Western countries (Kuhnimhof et al., 2012; Goodwin, 2012). With "soft" we mean policies that are based on some form of communication (instead of pricing or building infrastructure) and that appeal to population groups to voluntarily consider alternatives to private car usage (Bamberg et al., 2011). Various soft transport policies such as mobility management initiatives in Japan or travel awareness and public transport advertising campaigns in London have by now been successfully developed and assessed (Fujii \& Taniguchi, 2006, Cairns et al., 2008). The measures resulted in both road traffic reduction and impressive cost-benefit performance (Cairns et al., 2008). Theoretically, these communication measures generally consider attitudes, values and norms as fundamental factors that determine mobility patterns (Bamberg et al., 2011). With very few exceptions such socio-psychological factors of mode choice have not been investigated within a Chinese context yet. The underlying motivation for this study is therefore to understand whether "soft" transport policy measures could also be an option in Shanghai, and if yes, how such voluntary travel behavior change towards public transportation could be promoted.

We start with a brief review on how different psychological constructs are introduced and applied in various travel behavior modeling contexts. Then, partly following existing literature, we propose our model framework that focuses on the role of norming effects. Next, we describe how necessary data are collected through a survey, followed by a detailed report on the estimation results, their implications, and a comparison with findings from a study with German data. Finally, we summarize our findings and give comments on future work as well as practical policy implementation. 
The impact of individual socio-demographics, time or monetary cost on mode choice has been well documented in literature. Further, hybrid models incorporating latent instrumental values such as convenience, accessibility, and comfort are generally found superior in predicting public transport mode shares (Morikawa,1989; Walker, 2001; Yáñez, Raveau, \& Ortúzar, 2010). In particular, individual related symbolic/affective values like autonomy, excitement, status and privacy exert influences on travel mode alternative evaluation (Anable, \& Gatersleben, 2005; Hunecke, Haustein, Böhler \& Grischkat, 2010), and thus could be applied into TDM oriented traveler or trip segmentation. Similarly to car use there might be though further attitudinal factors that encourage people to use public transport such as pro-environmental attitudes, health reasons in the form that one is aware that excessive car usage might lead to lack of exercise, or deeper held values that might be summarized with a perception that "using public transport is the right thing to do" for the benefit to oneself and the surrounding society (Heath \& Gifford, 2002).

Yet psychological factors determining car /PT usage go beyond the above mentioned intra personal ones (e.g., intention, symbolic value, etc.). In more recent literature, inter personal factors or (social) norm effects have attracted much attention from scholars across disciplines (Bamberg et al., 2011; Abou-Zeid et al, 2013). Without any generally acknowledged definition, social norms describes the behavioral influence of others. Social norms refers to rules and standards that are understood by members of a group and that guide and/or constrain behavior without the force of the legal system but through interaction with others (Cialdini \& Trost, 1998). For example, one of the frequently referred contexts where social norms are important is public littering, i.e., one may or may not litter publicly due a perception whether littering is in line with the behavior as well as the expectation of others.

As in the example the terms perception and expectation indicate, social norms can be further segmented into different categories, accounting for different prescription and internalization degrees. Thøgersen has proposed an extended taxonomy categorizing norms first into descriptive and injunctive (Thøgersen, 2006). Descriptive norms (DN) refer to the perception on what is normal, i.e., what most people do (Cialdini, Reno, \& Kallgren, 1990; Fishbein \& Ajzen, 2011;Thøgersen, 2006). Compared to this, injunctive norms describe rules or beliefs as to what constitutes morally approved and disapproved conduct, that is, what should be done. Within injunctive norms, further differentiations can be made. Schwartz (1977) defines personal norms (PN) as self-expectation of specific action in a particular situation, experienced as a feeling of moral obligation, while subjective social norms (SSN) are enforced by expectations of externally administered rewards and/or sanctions (Thøgersen, 2006). We do notice different social norms taxonomies are parallelly employed in the literature (Matthies, \& Klöckner, 2012), however, we prefer the one by Thøgersen due to its clear hierarchical concept definition (Cialdini, Reno, \& Kallgren, 1990; Thøgersen, 2006).

There is by now a significant body of literature in environmental psychology demonstrating the importance of norming effects for behavioral decisions. Nordlund and Garvill (2003) for instance conclude that personal norms mediate the influence of values and problem awareness on 
willingness to reduce car usage. Similar empirical findings on subjective social norms could be found in Bamberg et al (2003). Their analysis on travel behavior of people who recently move to Stuttgart, Germany, suggests that neither past behavior nor direct habit are a good measure to predict future behavior. Instead attitude, perceived behavioral control and subjective norms are the main contributors for travel mode changes. An extensive review emphasizing on how descriptive norms influence mobility decision can be found in Abou-Zeid et al (2013). They review that there is ample evidence that for decisions such as whether to jay-walk, to illegally park bicycles, to commute by bicycle or to purchase cars norming effects are important. They conclude therefore that proper consideration of these norming effects can lead to more efficient design of (soft) transport policy measures.

\section{Literature with China applications}

To the best of our knowledge most of the studies to explain car ownership and PT usage respectively among the Chinese do not yet take into account norming effects nor attitudinal factors that have been found important to explain the effectiveness of soft transport policy measures. There are a few notable exceptions though:

Zhu et al (2012) has studied impacts of attitudes, social norms and aspiration for car ownership among Chinese university students. They suggest that socio-psychological aspects are the most influential determinant, having almost twice the effects than instrumental values on private car ownership. Thus they propose that measures aimed at changing attitudes towards cars as well as social norms should have a fundamental influence on car purchases and private car usage. Zhao et al (2012) conduct a web based survey among private car users in Shanghai regarding their PT usage intention and actual PT travel frequency with corresponding attitudinal constructs. They examine the validity of the Theory of Planned Behavior (TPB) in explaining car owners' PT usage intention with a multiple regression model. The significant influence of attitude, subjective norms as well as descriptive norms has been confirmed, though perceived behavioral control was found to be insignificant. The work by Lai and Chen (2011) focuses on factors affecting PT usage intention. Using survey data from Kaohsiung Mass Rapid Transit, they discuss the importance of "public transit involvement". They find that a person's feelings about the relevance or importance of public transport as well as service quality, perceived value and satisfaction all have significant positive effects on usage intention. Finally, as part of an international comparison, Belgiawan et al (2014) also collected some data from undergraduate students in Shanghai on car ownership motivations. They find that the perception of the car as a (negative) status symbol, the independence it creates as well as social norms all effect ownership motivations.

While the four studies analyze how attitudes, socio-demographics, and partially also social norms, affect car ownership and car or PT usage, they do not focus on identifying usage intentions and choice between modes which is the objective of this paper. Further, an aim of the present study is a systematic examination on the different norm categories discussed in the previous 
section and their specific influence on usage intentions.

\section{Hypotheses}

Besides the above quoted literature, a key reference for our study is the work by Bamberg et al (2007), on which we base parts of our hypotheses and methodology. With independent survey data from two German metropolitan areas, Bochum/Dortmund and Frankfurt, they first find empirical evidence in both samples that personal norm (PN) influences travel behavior but is mediated by the intent construct. They further demonstrate that social norms influence public transport usage intention via attitudes, perceived behavior control (PBC) and PN, while the feeling of guilt serves as a second determinant for PN. All the findings hold for both samples but with significant different path coefficients, motivating them to make a detailed comparison on influence of social contexts. In the current study, we partially replicate the Bamberg et al work with Chinese data with an emphasis on the norming effects. To derive policy suggestions we further aim to explain factors that create the perception of injunctive norms by individuals.

Our primary hypotheses are depicted in Fig. 1. Household private car ownership, public transport usage intention and actual usage frequency are selected as behavioral indicators. Generally, we are assuming both public transport usage intention and private car ownership are directly influenced by the same norms, but in opposing directions. Besides a direct effect, the influence of norms on public transport usage intentions should be mediated by private car ownership. Further in line with the empirical evidence by Bamberg et al (2007), norms do not influence actual public transport usage directly, but are mediated by intentions and private car ownership. We therefore hypothesize, as one might expect, that owning a private car reduces intentions to use public transport as well as the actual usage. The in Fig. 1 hypothesized effects of the demographics gender, age, income and education on mobility decisions are in line with a large set of literature, we agree though that some of the relationships are discussable and possibly context dependent. Higher education might in some cases only result in less public transport usage intentions due to (uncontrolled) correlation with income and car ownership. For example Schwanen et al (2001) studied leisure trips of older people and found that higher education can associate with more public transport usage.

To design and implement the aforementioned soft transport policies, it is necessary to conceptualize paths between norm constructs and behavior as in the norms activation model (NAM) by Schwartz (1977). NAM suggests that personal norms only influence behavior when two preconditions are met. First, individuals must be aware of potential consequences caused by the targeted actions for themselves and others. Second, they must feel a degree of personal responsibility for these actions and their potential consequences (Brown, 2007). Inherited from NAM, we introduce social problem awareness (SPA) as an activator of personal norms. Besides the well documented air pollution problem in Chinese cities, we investigate whether awareness (fear) of future possible fuel shortages, road congestion, traffic accident, health/obesity issues and social exclusion issues caused by excessive private car usage are perceived as problems. There is significant media coverage and public concerns on the pollution caused by car traffic and the resulting adverse health effects so that we hypothesize that those being more concerned about 
pollution would also have a stronger perception that car usage should be reduced. Similarly, obesity and a lack of exercise are issues nowadays more often perceived in connection with excessive car usage. Further, the rapid expansion of Shanghai and land-use changes that have come along with the increased car usage have also led to accessibility problems for some population groups.

In Fig. 1, latent variables are shown as ellipses while observed, manifest ones are in rectangles. The solid and dashed lines indicate hypothesized positive and negative association respectively. To reduce the number of arrows and crossings, we enclose the three norms constructs as well as the socio-demographic variables (i.e., gender, age, household monthly income category, and education level) with a sub box. For sake of brevity and clarity, we omit the manifest variables for the latent constructs, except for SPA, in the graphic description here and the following.

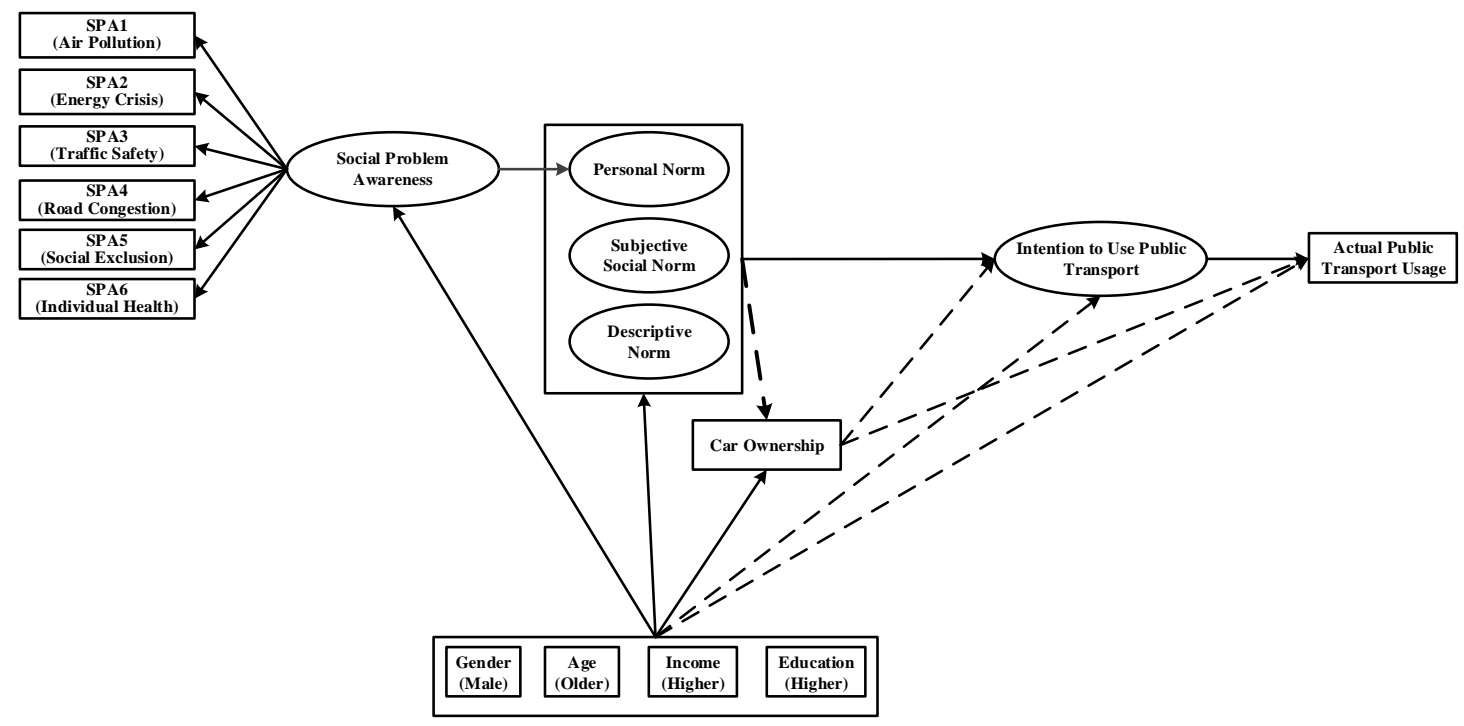

Fig.1 Hypothesized model structure

\section{Data collection and description}

A questionnaire was designed to collect the necessary information. We adopted an internet based survey and disseminated the link via a local bulletin board system and other social media in Shanghai. Compared to a paper based survey, this is both more cost and time effective and allows us to reach a wide spread sample. We note though a natural limitation of respondent bias by using this web based approach as younger people are more likely to access these bulletin board systems.

We paid each validated respondent an incentive of $10 \mathrm{CNY}$ (about 1.6 USD) in form of a mobile phone voucher. Within two days we collected 551 responses, among which 489 were completed. 24 respondents were excluded as they refused to provide any household monthly income information. This resulted in 465 responses that are the basis for the subsequent data analysis. The descriptive analysis in this section and the subsequent structural modeling was carried out with $\mathrm{R}$ version 3.0.2. 
Among all the validated responses, $25.8 \%$ were from female respondents, and $61.1 \%$ were distributed in the age range between 25 and 35 whereas according to the latest official statistics, in Shanghai, only 22.7\% of the whole population ages between 18 and 34 (Wang \& Ma, 2013). This bias in our sample should be due to the fact that young men are more active in sharing their opinions in online virtual communities. Income ranges were provided in the survey, after testing linear and loglinear structures we found that grouping answers into three categories provides better model fits and statistically significant parameters. The three groups were: Low (0-5,000CNY/ 815 USD, 20.9\%), Medium (5,000-11,000 CNY/1,794 USD, 46.5\%), and High (Above 11,000 CNY/ 1,794 USD, 32.7\%). Since the household income distribution for Shanghai was not publicly available, we calculated the average household monthly income of the year 2012 by multiplying the monthly income per capita and average household size, resulting in 8,355 CNY (1,343 USD) (Wang \& Ma, 2013) which fell into the Medium income category. 90\% of the respondents report holding a bachelor's degree and $47.3 \%$ own a car (Table 1). The private car ownership rate for the whole city is 64.5 cars per 1,000 population (Wang \& Ma, 2013). It should be noted that this only includes private cars with locally registered number plates. If non-local registered private cars are also considered simultaneously, it increases to roughly 100 cars per 1,000 population (Wang \& Ma, 2013). Nevertheless, the age, education and the car ownership data show that, compared to the general Shanghai population, our sample is clearly skewed towards the younger and better educated who are also more likely to own cars. Though we control for these socio demographics in our subsequent models these biases should be kept in mind when generalizing our results to a wider population.

About $54 \%$ of the respondents used public transport more than 10 times per week which might imply that they use it for commuting which appears reasonable given the car ownership rate of our sample as well as the average daily trip rate for the whole population in Shanghai, i.e., 2.23 trips per person and day, according to the Comprehensive Traffic Survey Report in 2009 (Lu, 2010). 
Table 1 Descriptive statistics for demographics

\begin{tabular}{|c|c|c|c|c|}
\hline Demographics & Level & $\mathbf{N}$ & $\%$ & Cum \% \\
\hline \multirow[t]{2}{*}{ Sex } & Female & 120 & 25.81 & 25.81 \\
\hline & Male & 345 & 74.19 & 100.00 \\
\hline \multirow{7}{*}{ Age category } & $0-20$ yrs & 14 & 3.01 & 3.01 \\
\hline & $20-25$ yrs & 60 & 12.90 & 15.91 \\
\hline & $25-30 \mathrm{yrs}$ & 151 & 32.47 & 48.39 \\
\hline & $30-35$ yrs & 133 & 28.60 & 76.99 \\
\hline & $35-40 \mathrm{yrs}$ & 52 & 11.18 & 88.17 \\
\hline & $40-45$ yrs & 29 & 6.24 & 94.41 \\
\hline & $45+\mathrm{yrs}$ & 26 & 5.59 & 100.00 \\
\hline \multirow{3}{*}{ Monthly income } & $0-5,000 \mathrm{CNY} / 815 \mathrm{USD}$ & 97 & 20.86 & 20.86 \\
\hline & 5,000-11,000 CNY/1,794 USD & 216 & 46.45 & 67.31 \\
\hline & Above $11,000 \mathrm{CNY} / 1,794$ USD & 152 & 32.69 & 100.00 \\
\hline \multirow{4}{*}{ Highest Education } & No university degree & 45 & 9.68 & 9.68 \\
\hline & Bachelor degree & 367 & 78.92 & 88.60 \\
\hline & Master degree & 46 & 9.89 & 98.49 \\
\hline & Doctoral degree & 7 & 1.51 & 100.00 \\
\hline \multirow[t]{2}{*}{ Car ownership } & No & 245 & 52.69 & 52.69 \\
\hline & Yes & 220 & 47.31 & 100.00 \\
\hline \multirow{4}{*}{ Weekly PT use frequency } & Less than 5 times & 108 & 23.23 & 23.23 \\
\hline & 5-10 times & 106 & 22.80 & 46.02 \\
\hline & $10-15$ times & 172 & 36.99 & 83.01 \\
\hline & More than 15 times & 79 & 16.99 & 100.00 \\
\hline
\end{tabular}

2

\section{Questions used for the Latent Constructs}

Measures are needed to manifest the socio-psychological orientation of the respondents. As one objective of the current work is to partially replicate the work by Bamberg et al (2007), i.e. to check whether soft TDM measures derived from the socio-psychological theories apply in Shanghai similar to German cities, we used the same indicator questions for our subjective social norm (SSN) and personal norm (PN) constructs as well as for intention to use public transport (IUPT). When preparing the questionnaire, Bamberg and his colleagues organized a pre-study by asking their targeted respondents to qualitatively enumerate questions intended for latent traits construction. The most referred items then were standardized and included in the questionnaire, and had their measuring ability tested with data from the formal survey afterwards (Bamberg \& Schmidt, 2003).

We advance the Bamberg et al (2007) study though by extending our questions used to measure social problem awareness (SPA) associated with car usage. As noted in the hypothesis section, we picked up the six negative consequences frequently discussed in public media and literature to test to what extent one perceives these as social problems caused by excessive car usage. 
Bamberg et al also do not explicitly distinguish descriptive norms (DN). To design appropriate questions we find two approaches in the literature, one concerning the percentage of people around the respondent conducting specific activities (Fishbein \& Ajzen, 2011) while the second emphasizes more on the observed activity frequency (Borsari \& Carey, 2003; Sheppard, 2011). We prefer the latter, as unlike taking drugs or alcohol, which where some of the applications for the former, most citizens in Shanghai will use public transport at least very occasionally.

After some initial tests and to keep an appropriate length for the final questionnaire, two statements each were included for subjective social norms (SSN), personal norms (PN), and intention to use public transport (IUPT) respectively. For each statement, respondents were asked to rate on a 5 point Likert scale (from " $1=$ strongly disagree" to " $5=$ strongly agree"). Regarding descriptive norms, the respondents were asked to report their perceived public transport usage frequency of four different groups of people around them, with a scale from " $1=$ Do not use at all" to " $5=$ Always use". Table 2 lists the questions that were used to build these constructs as well as SPA including their source. Judging from the mean values, we found that respondents hold a positive attitude towards the public transport service in Shanghai as their marked scores exceeded the neutral point of the scale. The standard deviation was quite evenly distributed around 0.8 giving us sufficient variation for our subsequent analysis. Among the six social problem awareness factors we find that traffic accidents followed by air pollution and congestion are rated as the most significant problems caused by private car usage which is fairly in line with our expectations. 
Table 2 Constructs and statements

\begin{tabular}{|c|c|c|c|c|c|c|}
\hline \multirow[b]{2}{*}{ Constructs/Statements } & \multicolumn{2}{|c|}{ Measures } & \multirow[b]{2}{*}{$\Lambda$} & \multirow{2}{*}{$\begin{array}{l}\text { Item total } \\
\text { correlation }\end{array}$} & \multirow{2}{*}{$\begin{array}{l}\text { Alpha if } \\
\text { item } \\
\text { deleted }\end{array}$} & \multirow{2}{*}{$\begin{array}{c}\text { Cronbach } \\
\text { alpha }\end{array}$} \\
\hline & Mean & Std.Dev. & & & & \\
\hline \multicolumn{7}{|l|}{ Social problems awareness(SPA) (Designed by the authors) } \\
\hline $\begin{array}{l}\text { There is urgent need to deal with fine particulate matter } \\
\text { (PM 2.5, PM10 etc.) from private car usage (SPA1). }\end{array}$ & 3.88 & 0.81 & 0.618 & 0.59 & 0.59 & \multirow{6}{*}{0.66} \\
\hline $\begin{array}{l}\text { Due to too much private car usage now, in the near } \\
\text { future we will encounter problems due to not enough } \\
\text { petrol for cars (SPA2). }\end{array}$ & 3.54 & 0.95 & 0.551 & 0.52 & 0.60 & \\
\hline $\begin{array}{l}\text { There are urgent needs to deal with traffic accidents } \\
\text { (SPA3). }\end{array}$ & 4.01 & 0.77 & 0.387 & 0.38 & 0.64 & \\
\hline $\begin{array}{l}\text { There is need to limit the amount of private car traffic in } \\
\text { large towns and cities during busy times of day (SPA4). }\end{array}$ & 3.79 & 0.96 & 0.480 & 0.46 & 0.62 & \\
\hline $\begin{array}{l}\text { The increase in private car usage in the past years has } \\
\text { made it difficult for some people to reach real needed } \\
\text { amenities (e.g., medical, education, government, } \\
\text { shopping, etc.) (SPA5). }\end{array}$ & 3.58 & 0.89 & 0.498 & 0.49 & 0.61 & \\
\hline $\begin{array}{l}\text { Using private car every day causes people to become } \\
\text { overweight easily (SPA6). }\end{array}$ & 3.81 & 0.89 & 0.436 & 0.44 & 0.63 & \\
\hline \multicolumn{7}{|l|}{ Subjective social norms(SSN) (Bamberg et al, 2007) } \\
\hline $\begin{array}{l}\text { People who are important to me think that I should use } \\
\text { public transport instead of the car for everyday routes } \\
\text { (SSN1). }\end{array}$ & 3.49 & 0.88 & 0.955 & 0.77 & -- & \multirow[t]{2}{*}{0.82} \\
\hline $\begin{array}{l}\text { People who are important to me would support my } \\
\text { public transport usage (SSN2). }\end{array}$ & 3.62 & 0.84 & 0.733 & 0.77 & & \\
\hline \multicolumn{7}{|l|}{ Personal norms $(P N)$ (Bamberg et al, 2007) } \\
\hline $\begin{array}{l}\text { Because of my own values/principles I feel an } \\
\text { obligation to use public transport instead of private car } \\
\text { for everyday trips here in my city (PN1). }\end{array}$ & 3.49 & 0.8 & 0.861 & 0.58 & \multirow[t]{2}{*}{-- } & 0.63 \\
\hline $\begin{array}{l}\text { I feel guilt to use private car when I could use public } \\
\text { transport (PN2). }\end{array}$ & 3.05 & 0.93 & 0.532 & 0.58 & & \\
\hline \multicolumn{7}{|c|}{ Descriptive norms $(D N)$ : What's the public transport usage frequency of people in the following category? (Designed by the authors) } \\
\hline My family members in Shanghai... (DN1). & 3.59 & 0.9 & -- & 0.59 & 0.82 & \multirow{4}{*}{0.82} \\
\hline My friends in Shanghai... (DN2). & 3.57 & 0.83 & 0.710 & 0.76 & 0.74 & \\
\hline My colleagues in Shanghai... (DN3). & 3.63 & 0.77 & 0.869 & 0.77 & 0.75 & \\
\hline People in my living community in Shanghai ... (DN4). & 3.66 & 0.72 & 0.747 & 0.73 & 0.76 & \\
\hline \multicolumn{7}{|l|}{ Intention to use public transport(IUPT) (Bamberg et al, 2007) } \\
\hline $\begin{array}{l}\text { I intend to use public transport for everyday trips } \\
\text { (IUPT1). }\end{array}$ & 3.76 & 0.8 & 1.173 & 0.8 & \multirow[t]{2}{*}{--} & \multirow[t]{2}{*}{0.85} \\
\hline $\begin{array}{l}\text { My intention to use public transport for everyday trips } \\
\text { is: very weak }(1) \rightarrow \text { very strong (5) (IUPT2). }\end{array}$ & 3.62 & 0.83 & 0.626 & 0.8 & & \\
\hline
\end{tabular}




\section{Model estimation}

\section{Reliability of Latent Constructs}

Consistency for all the latent constructs was examined. We firstly test the reliability of our latent constructs with Cronbach's alpha analysis. By convention, an alpha near 0.70 is considered "adequate", though values above 0.80 are desired (Vaske, 2008). We further report corrected item-total correlations in Table 2, which should be larger than 0.40 (Schmitt, 1996; Vaske, 2008). Moreover, a set of scale items can have a high Cronbach's alpha but still be multidimensional, when there are separate clusters of items having high inter-correlations. In this case, Cronbach and Shavelson (2004) assert that Cronbach's alpha can correctly be used for heterogeneous scales, but that additional analysis such as confirmatory factor analysis (CFA) is required to remove uncertainty. Goodness of fit indices include the Comparative Fit Index (CFI), Non-Normed Fit Index (NNFI, also known as TLI), Adjusted-Goodness-of-Fit Index (AGFI), StandardizedRoot-Mean-Square-Residual (SRMR). An acceptable model fit is indicated when CFI, NFI, and AGFI are greater than 0.90, while SRMR should be less than 0.10 (Kline, 2011).

Corrected item-total correlation and CFA fit indices are reported in Tables 2 and 3 respectively. The indices are acceptable except for DN, for which the AGFI and TLI do not meet the 0.9 cut-off criteria. We considered dropping DN1 as Cronbach's alpha for DN does not change significantly and the latent construct by DN2, DN3, and DN4 could then meet the AGFI and TLI criteria (see Table 3). However, such treatment loses information of family influence on one's behavior, and, as one anonymous reviewer kindly suggested, it would be interesting to examine the difference of variously oriented descriptive norms on one's travel decision. Thus in the following analysis, we split the four DN statements into two groups, one with DN1 only and used to formulate a Family Descriptive Norms (FDN) construct, while the second one including the other three statements used for a Non-family Descriptive Norms (NFDN) construct.

Table 3 Reliability analysis-CFA approach

\begin{tabular}{|c|c|c|c|c|}
\hline Constructs & AGFI & SRMR & CFI & TLI \\
\hline Social problems awareness & 0.986 & 0.022 & 1.000 & 1.000 \\
\hline Subjective social norms & 1.000 & 0.000 & 0.997 & 1.000 \\
\hline Personal norms & 1.000 & 0.000 & 0.991 & 1.000 \\
\hline \multirow{2}{*}{ Descriptive norms } & 0.817 & 0.042 & 0.948 & 0.844 \\
\hline & 1.000 & 0.000 & 1.000 & 1.000 \\
\hline Intention to use public transport & 1.000 & 0.000 & 0.997 & 1.000 \\
\hline
\end{tabular}

Correlation analysis

Based on the CFA analysis, Table 4 presents the correlations among the socio-demographics and latent constructs. Our hypotheses appear well supported except for the effect of gender and PN. Gender does not significantly correlate with any other variable even at a 0.1 significance level, 
1

Table 4 Correlation of the socio-demographics and the five latent constructs

\begin{tabular}{|c|c|c|c|c|c|c|c|c|c|c|c|c|}
\hline & Gender & Age & Income & EDU & SPA & SSN & PN & NFDN & FDN & IUPT & CAR & PTU \\
\hline Gender & 1.000 & & & & & & & & & & & \\
\hline Age & -0.026 & 1.000 & & & & & & & & & & \\
\hline Income & -0.046 & $0.291 *$ & 1.000 & & & & & & & & & \\
\hline EDU & -0.001 & -0.043 & $0.214 *$ & 1.000 & & & & & & & & \\
\hline SPA & -0.028 & -0.147 & -0.113 & -0.047 & 1.000 & & & & & & & \\
\hline SSN & -0.022 & -0.039 & -0.083 & -0.026 & $0.355 *$ & 1.000 & & & & & & \\
\hline $\mathrm{PN}$ & -0.054 & -0.040 & -0.052 & 0.018 & $0.347 *$ & $0.567 *$ & 1.000 & & & & & \\
\hline NFDN & -0.002 & 0.006 & -0.008 & -0.057 & 0.144 & 0.134 & -0.014 & 1.000 & & & & \\
\hline FDN & 0.038 & 0.022 & 0.018 & -0.033 & 0.105 & 0.079 & -0.039 & $0.528 *$ & 1.000 & & & \\
\hline IUPT & -0.048 & -0.123 & -0.149 & -0.096 & $0.314^{*}$ & $0.494^{*}$ & $0.418 *$ & $0.208^{*}$ & 0.150 & 1.000 & & \\
\hline CAR & -0.051 & $0.163^{*}$ & $0.292 *$ & 0.144 - & $-0.225 *$ & -0.107 & -0.061 & $-0.193 *$ & $-0.212 *$ & $-0.335 *$ & 1.000 & \\
\hline PTU & 0.006 & $-0.208 *$ & -0.125 & -0.013 & $0.183^{*}$ & $0.307 *$ & $0.242 *$ & $0.226^{*}$ & $0.163^{*}$ & $0.443 *$ & $-0.315 *$ & 1.000 \\
\hline
\end{tabular}

Note: Italic $p<0.1$, bold $p<0.05$, bold* $p<0.01$; SPA = Social Problem Awareness; SSN= Subjective Social Norms; PN= Personal Norms; NFDN= Non-family Descriptive Norms; FDN=Family Descriptive Norms; IUPT= Intention to Use Public Transport; CAR = Car Ownership Status; PTU=Actual Weekly Public Transport Usage.

Path analysis with SEM method

We note that introducing the binary variable car ownership as explanatory variable introduces some additional complexity as it violates the multinormality assumption underlying commonly used estimation software such as LISREL (Bamberg \& Schmidt, 2003). This estimation problem is tackled by using the weighted least squares means and variance adjusted (WLSMV) estimator in Mplus and the diagonally weighted least squares (DWLS) in the R Lavaan package. For details we refer the reader to the Mplus and Lavaan manuals (Muthén \& Muthén, 2010; Rosseel, 2013). Fig. 2 shows our estimated model and Table 5 the estimation of our latent constructs. Gender is dropped from the model in line with the insignificant correlations reported in Table 4. The idea that SPA might be influenced by the socio-demographics is not supported by our data either, so the links are not included in Fig.2. Following index thresholds suggested in Kline (2011) our model fit appears acceptable $\left(\chi^{2}=409.461, d f=175, p<0.001\right.$, GFI $=0.973$, AGFI=0.962, RMSEA=0.054; $\mathrm{NNFI}=0.936, \mathrm{CFI}=0.946$ ). In the following we discuss first the influences of socio-demographics and then focus on our norms constructs. 
1

2

3

\begin{tabular}{cllcccc}
\hline Construct & & Manifest variables & Estimate & Std. Estimate & Std. Error & $\boldsymbol{p}$-value \\
\hline SSN & $\rightarrow$ & SSN1 & 1 & 0.838 & 0 & NA \\
SSN & $\rightarrow$ & SSN2 & 1.002 & 0.886 & 0.055 & $p<0.001$ \\
PN & $\rightarrow$ & PN1 & 1 & 0.960 & 0 & NA \\
PN & $\rightarrow$ & PN2 & 0.633 & 0.523 & 0.073 & $p<0.001$ \\
NFDN & $\rightarrow$ & DN2 & 1 & 0.791 & 0 & NA \\
NFDN & $\rightarrow$ & DN3 & 0.932 & 0.794 & 0.080 & $p<0.001$ \\
NFDN & $\rightarrow$ & DN4 & 0.783 & 0.716 & 0.066 & $p<0.001$ \\
FDN & $\rightarrow$ & DN1 & 1 & 1 & 0 & NA \\
SPA & $\rightarrow$ & SPA1(Air pollution) & 1 & 0.532 & 0 & NA \\
SPA & $\rightarrow$ & SPA2(Energy crisis) & 0.846 & 0.389 & 0.108 & $p<0.001$ \\
SPA & $\rightarrow$ & SPA3(Traffic safety) & 0.565 & 0.318 & 0.085 & $p<0.001$ \\
SPA & $\rightarrow$ & SPA4(Road congestion) & 1.176 & 0.536 & 0.124 & $p<0.001$ \\
SPA & $\rightarrow$ & SPA5(Social exclusion) & 0.925 & 0.450 & 0.121 & $p<0.001$ \\
SPA & $\rightarrow$ & SPA6(Health) & 0.877 & 0.425 & 0.110 & $p<0.001$ \\
IUPT & $\rightarrow$ & IUPT1 & 1 & 0.790 & 0 & NA \\
IUPT & $\rightarrow$ & IUPT2 & 1.122 & 0.855 & 0.049 & $p<0.001$ \\
\hline
\end{tabular}

Fig. 2 Path analysis graphic description

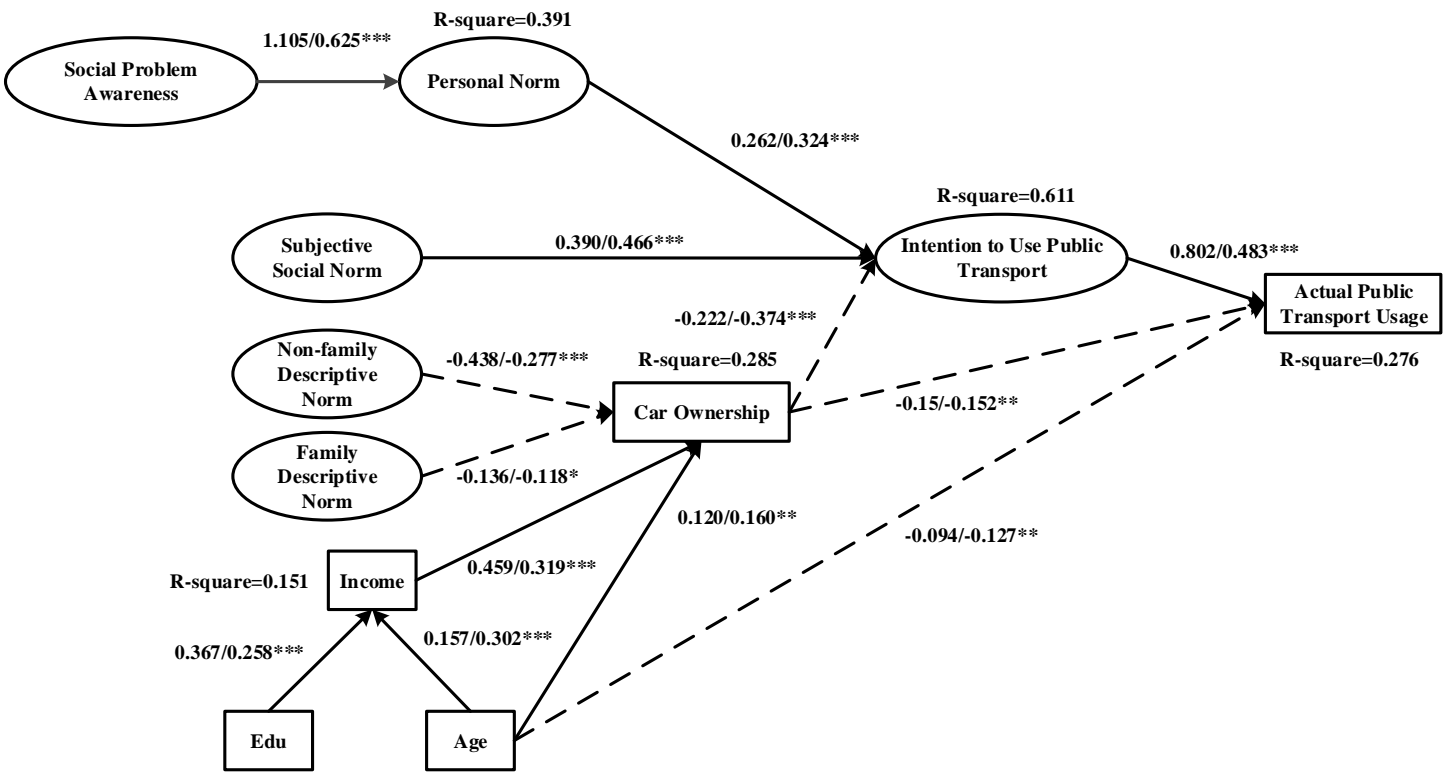

Notes: For each path we show: unstandardized coefficient/ standardized coefficient, ***significant at the 0.001 level, ** significant at the 0.01 level, * significant at the 0.1 level

Table 5 Loadings for latent constructs 
Influences of socio-demographics

Older respondents or those with higher education tend to have higher income. Income then influences car ownership directly and indirectly PT usage, which illustrates that despite recent investments in the public transport system in Shanghai higher income is associated with higher car ownership, possibly due to both symbolic affective factors as well as convenience associated with car trips. Private car ownership also mediates the effect of age on public transport usage intention and frequency. In particular in China this is corresponding to our expectations as it takes time for younger people to save sufficient money to afford a private car. We further find age to be directly negatively associated with PT usage. Considering that our sample predominately consists of people aged below 50 we suggest that an explanation is the more active and irregular lifestyle of younger Shanghainese. Trip surveys from Shanghai suggest that people aged in their 20s make on average 2.6 trips per day whereas those aged in their 50s make on average only 2.3 trips per day (Lu, 2010). Fig.2 also reveals that education affects travel behavior indirectly via income and household car ownership, i.e., a higher education first promotes one's income, then the possibility to own a car in her/his family, thus reduces her/his intention to use PT as well as the actual usage.

\section{Influences of norms}

All the four norms constructs influence the individual's intention to use PT and increase their actual PT trip frequency. The estimated model structure suggests though that SSN, PN, NFDN and FDN influence individual travel behavior via different paths and with different intensity. While SSN and PN first affect one's intention to use PT and then the actual behavior, both NFDN and FDN effects are further mediated by the respondent's household car ownership. Hence, the degree to which, family members and others, use public transport (and not private car) influences the respondents' household car ownership status. Controlling for this mediation effect we do not find a significant direct path from either NFDN or FDN to usage intentions. We note that the DN effect is likely to be a mixture of various factors that we cannot control for with our data, such as similarity in lifestyle, income as well access to public transport in the neighborhood or the workplace. In addition the path might cover some of the "learning and status effects" associated with trends, i.e. that one wants to assimilate the behavior to others in one's social network. We would expect the latter effect to be more significant for our NFDN construct and the former set of factors (lifestyle, access to PT etc.) to be more related to FDN. It is therefore interesting to observe that regarding impacts on private car ownership, we find a higher path coefficient for NFDN than for FDN even though the correlation information (Table 2) suggests the opposite.

Table 6 shows the different path strengths of independents on travel behavior and distinguishing direct, indirect and total effects. The table illustrates that car ownership is mostly influenced by income but also reduced by high perceived DN constructs to a comparable extent. 
Table 6 Total standardized paths effects

\begin{tabular}{|c|c|c|c|c|c|c|c|c|c|c|c|}
\hline$\rightarrow$ & AGE & INC & EDU & SPA & SSN & PN & NFDN & FDN & CAR & IUPT & PTU \\
\hline AGE & & 0.302 & & & & & & & $0.256^{\Delta \Delta}$ & $-0.06^{\Delta}$ & $-0.212^{\Delta \Delta}$ \\
\hline INC & & & & & & & & & 0.319 & $-0.119^{\Delta}$ & $-0.106^{\Delta}$ \\
\hline EDU & & 0.258 & & & & & & & $0.082^{\Delta}$ & $-0.031^{\Delta}$ & $-0.027^{\Delta}$ \\
\hline SPA & & & & & & 0.625 & & & & $0.203^{\Delta}$ & $0.098^{\Delta}$ \\
\hline SSN & & & & & & & & & & 0.466 & $0.225^{\Delta}$ \\
\hline PN & & & & & & & & & & 0.324 & $0.157^{\Delta}$ \\
\hline NFDN & & & & & & & & & -0.277 & $0.103^{\Delta}$ & $0.092^{\Delta}$ \\
\hline FDN & & & & & & & & & -0.118 & $0.044^{\Delta}$ & $0.039^{\Delta}$ \\
\hline CAR & & & & & & & & & & -0.374 & $-0.333^{\Delta \Delta}$ \\
\hline IUPT & & & & & & & & & & & 0.483 \\
\hline
\end{tabular}

Our analysis suggests that 1 unit increase in SSN would cause an average 0.466 units increase in intention to use public transport (IUPT), which is larger than the effect of PN $(0.324$ units) and DN (0.103 units for NFDN and 0.044 units for FDN). Increase in income and age also results in a decrease in IUPT among our sample, though at a relatively low rate. As noted, such negative effects are indirect, implying that age, income and education increase per se does not necessarily reduce travelers' intention to use public transport. Since actual PT usage is strongly positively correlated with IUPT, the norms positively influence PT usage while private car ownership, income and age reduce PT usage. Mediated by IUPT, the coefficients for norms are smaller than those of the "resistors" though taken together still of considerable size and can counter the effect of the socio-demographic factors covered in our survey. Another finding that appears important to us when comparing the standardized coefficients for the paths from norms to IUPT and PTU is that among the four norms SSN has the most significant effect. This suggests that perceptions of others' opinion are an important element in the intention and actual usage of public transport.

\section{Activation of personal norms}

We further find that PN is activated by social problem awareness. As can be seen from the upper left of Fig. 2, SPA alone explains nearly $40 \%$ variance of PN. SPA is constructed with six manifest variables. Our estimates reveal that according to the standardized coefficients of each manifest variable, subjects' concern on particulate matter (SPA1) and road congestion (SPA4) are most influential with nearly the same coefficients ( 0.532 and 0.536 respectively), followed by social exclusion (SPA5, 0.450) and health (SPA6, 0.425). Energy issues (SPA2, 0.389) and traffic accident (SPA3, 0.318) contribute least. The larger coefficients for air pollution and road congestion might be expected given the daily exposure of citizens to these issues. The significance of perception of social exclusion might be surprising but indicates that the increase in car traffic has led to some real issues for some communities and population groups as perceived by some. 
Similarly, the role of SPA2 does suggest that those who are aware of peak oil discussions are more aware of general problems caused by excessive car usage and hence do not perceive cars as much as a status symbol. Interestingly we find a fairly low coefficient for SPA3 (Traffic safety) despite it being rated highly as a problem (Table 2). This suggests that the risk of accidents is perceived but does not necessarily change the perception of the car.

\section{Comparison with work of Bamberg et al. (2007)}

Finally, as noted, parts of our paper follow the Bamberg et al. (2007) approach and we can hence compare the present findings from Shanghai with their two German case studies. Bamberg et al report model fits with and without consideration of PT past usage for their Frankfurt case study but only the Bochum case study reports results without habitual factors. These models without habitual factors we use here for comparison and we pick up the common paths for both models (Table 7). We note that the signs of all paths are in line and that our estimated coefficients mostly appear to be in range with the Bamberg et al.'s (2007) results. The exception is our larger estimate of SPA on PN (though the correlation is also similar). We note though that our SPA construct differs from theirs in that we include more aspects.

In all samples we find that SSN has a stronger effect on PT usage than PN. This implies the importance of the external social environment towards behavior. Bamberg et al argue further that SSN is an important source of PN (Bamberg et al., 2007). Our results suggest that SSN and PN effects in Shanghai do not differ significantly compared to a German context. Bamberg et al discuss that social context is important to understand the impact of SSN and our results might show how "Westernized" Shanghai has already become. To be more general, one might hypothesize in an Asian context a stronger effect of SSN as the influence of others on one's decision making might be more pronounced in more collective societies. Belgiawan et al (2014) for example show that social norms correlate higher with car ownership intentions in Asian countries than in the Netherlands.

Table7 Common paths effects for the three samples (standardized)

\begin{tabular}{lccc}
\hline \multirow{2}{*}{ Paths } & \multicolumn{3}{c}{ Estimated effects (Correlation) } \\
\cline { 2 - 4 } & Frankfurt & Bochum & Shanghai \\
\hline IUPT $\rightarrow$ PTU & $0.730(0.75)$ & $0.450(0.48)$ & $0.483(0.443)$ \\
SSN $\rightarrow$ IUPT & $0.695(0.70)$ & $0.237(0.35)$ & $0.466(0.494)$ \\
$\mathbf{P N \rightarrow \text { IUPT }}$ & $0.400(0.82)$ & $0.200(0.29)$ & $0.324(0.418)$ \\
SSN $\rightarrow$ PTU & $0.507(0.53)$ & $0.107(0.03)$ & $0.225(0.307)$ \\
$\mathbf{P N ~} \rightarrow$ PTU & $0.292(0.60)$ & $0.090(0.16)$ & $0.157(0.242)$ \\
SPA $\rightarrow$ PN & $0.378(0.36)$ & $0.486(0.37)$ & $0.625(0.347)$ \\
\hline
\end{tabular}

\section{Summary and discussion}

Our discussion starts by pointing out transportation problems in China and specifically Shanghai. Private car ownership is expected to increase further in the predictable future as well as the apparent problems associated with this. Given this background and the need to design alternative 
policies, in this paper we explore the structural relationship between problem awareness, norms, and public transport usage, controlling for car ownership and public transport usage intentions. Our focus is on the role of norms which we split into personal, social and descriptive norms.

We find that most of our assumptions based on existing literature are confirmed by our model. In particular income has the expected significant positive effect on car ownership while its effects on intended and actual public transport usage are much smaller. The norm constructs explain public transport usage to a larger degree. We discuss the importance to distinguish the interpretation of the three norms constructs. Descriptive norms will be related to missing variables in our survey regarding the public transport service quality in one's neighborhood. In further work, with a more detailed survey, it would be interesting to distinguish the effect of these factors from the "influence of observing others". It is therefore difficult to derive policy implications from descriptive norms for the time being, except that our distinction between descriptive norms derived from family members and others suggests that indeed the perception of how non-family members use public transport might be an important factor for car ownership decisions. Furthermore, it is worth observing that the factors combined into descriptive norms appear to explain car ownership as much as income suggesting the potential for a good quality public transport service to reduce car ownership.

Subjective social norms and personal norms are instead rather suitable to discuss the potential for soft transport policies. The significant effect of SSN suggests that perceived social pressure could be used to increase the willingness to use public transport. If one could initiate an increase in public transport usage, this might turn into a larger trend as people appear to consider the expectation of others. Our findings regarding personal norms further strengthen this argument. The construct describes the more internalized aspects of social pressure. Convictions about the car as status symbol and public transport as "transport for the less well-off" appear to (still) exist in Shanghai as also observed by Zhu et al (2012) among students. Changing this perception could have significant impacts on mode choice and car purchases.

We believe that our observation that PN can be explained to a significant degree by problem awareness has further policy implications. We have noted the importance of congestion perception and air pollution in our problem awareness construct. Taken together, and based on our causal assumptions, our path analysis suggests that personal norms are most activated by the problems that are also most in the news currently, namely air pollution and congestion. This might be further evidence that mobility patterns could be influenced by letting people realize the various negative consequences associated with car usage. If awareness of negative health, environmental as well as economic effects associated with car usage and congestion could be further raised, one might also find more willingness among the citizens of Shanghai to reconsider their mobility decisions.

One might hence utilize the growing discussion on air pollution in China to motivate behavioral changes. Tan (2013) reports that $26.4 \%$ of her survey respondents from Changsha, the capital city of the Hunan province, China, would like to reduce their private car usage due to the worsening air quality. Our study confirms that such problem awareness induces personal norms which in turn influence intentions to use public transport.

Referring back to our hypotheses illustrated in Fig.1, our results are based on the assumption 
that the perceived personal norms are activated by social problem awareness. We suggest that respondents who are more aware of the various negative effects of excessive car usage perceive a higher obligation to use more public transport instead of private car. We note that the reverse causality, i.e. justifying one's perception and behavior by creating a set of believes on how bad car traffic is seems less likely, especially since we do not find a strong correlation between income and SPA (nor between income and PN). In short, a "cognitive dissonance" argument that those who cannot afford cars project a negative image on cars appears therefore unlikely, though generally we cannot exclude the possibility that car users downplay the negative consequences of car usage.

Based on these findings we therefore suggest that also in Shanghai (as well as other Chinese cities) the implementation of soft policy measures such as mobility management, work place transport schemes and other kinds of appeals and advertisement schemes for sustainable transport should be more considered in addition to currently widely debated coercive ones. A perception often held that Chinese cities first have to improve transit infrastructure before additional measures are taken might be misleading. Rather, we believe our discussion on the three norms constructs suggests that both hard and soft policy measures should be combined.

Our study clearly leaves ample room for further research. We pointed out the ambiguity of the descriptive norms term and suggest that aiming to solve this by a more detailed survey on the experienced public transport quality could be worthwhile to derive additional specific policy suggestions. Further, connected to above paragraph, it would be worth observing how social problem awareness changes with growing environmental problems. Such kind of panel data could further support the cause and effect assumptions made in our path analysis. Finally, it is our hope that this study contributes to the study of specific mobility management schemes also in China.

\section{Acknowledgement}

The authors would like to acknowledge Dr. Teng Jing (Tongji University, China) and Miss Yu Yixiu (now a PhD student in Texas Tech University, USA) for their helpful assistance in questionnaire distribution and incentive assignment respectively. We also gratefully acknowledge three anonymous reviewers who gave critical and valuable suggestions that helped improve the manuscript.

\section{References}

Abou-Zeid, M., Schmöcker, J., Belgiawan, P. F., \& Fujii, S. (2013). Mass effects and mobility decisions. Transportation Letters, 5(3), 115-130.

Anable, J., \& Gatersleben, B. (2005). All work and no play? The role of instrumental and affective factors in work and leisure journeys by different travel modes. Transportation Research Part A: Policy and Practice, 39(2), 163-181.

Bamberg, S., Fujii, S., Friman, M., \& Gärling, T. (2011). Behaviour theory and soft transport policy measures. Transport policy, 18(1), 228-235.

Bamberg, S., Hunecke, M., \& Blöbaum, A. (2007). Social context, personal norms and the use of 
public transportation: Two field studies. Journal of Environmental Psychology, 27(3), 190-203. doi: 10.1016/j.jenvp.2007.04.001.

Bamberg, S., R Lle, D., \& Weber, C. (2003). Does habitual car use not lead to more resistance to change of travel mode? Transportation, 30(1), 97-108. doi: 10.1023/A:1021282523910.

Bamberg, S., \& Schmidt, P. (2003). Incentives, morality, or habit? Predicting students' car use for University Routes with the models of Ajzen, Schwartz, and Triandis. Environment and Behavior, 35(2), 264-285. doi: 10.1177/0013916502250134.

Belgiawan, P. F., Schmöcker, J., Abou-Zeid, M., Walker, J., Lee, T., Ettema, D. F.,... Fujii, S. (2014, 2014-01-01). Car Ownership Motivation Among Undergraduate Students in China, Indonesia, Japan, Lebanon, Netherlands, Taiwan, and U.S.A. Paper presented at the Transportation Research Board 93rd Annual Meeting.

Borsari, B., \& Carey, K. B. (2003). Descriptive and injunctive norms in college drinking: A meta-analytic integration. Journal of studies on alcohol,64(3), 331.

Brown, L. V. (2007). Psychology of Motivation: Nova Publishers.

Cairns, S., Sloman, L., Newson, C., Anable, J., Kirkbride, A., \& Goodwin, P. (2008). Smarter choices: assessing the potential to achieve traffic reduction using 'soft measures'. Transport Reviews, 28(5), 593-618.

Cialdini, R. B., Reno, R. R., \& Kallgren, C. A. (1990). A focus theory of normative conduct: Recycling the concept of norms to reduce littering in public places. Journal of personality and social psychology, 58(6), 1015.

Cialdini, R. B., \&Trost, M. R.(1998). Social influence: Social norms, conformity and compliance. The handbook of social psychology, Vols. 1 and 2 (4th ed.)., (pp. 151-192). New York, NY, US: McGraw-Hill, x, 1085 pp.

Colliers International, Parking Rates Broadly Up - Worldwide, from http://www.thetruthaboutcars.com/wp-content/uploads/2011/07/globalcolliersparkingratesurvey2011.p df, accessed December 26, 2013.

Cronbach, L. J., \& Shavelson, R. J. (2004). My current thoughts on coefficient alpha and successor procedures. Educational and psychological measurement, 64(3), 391-418.

Fishbein, M., \& Ajzen, I. (2011). Predicting and changing behavior: The reasoned action approach: Taylor \& Francis.

Fujii, S., \& Taniguchi, A. (2006). Determinants of the effectiveness of travel feedback programs-a review of communicative mobility management measures for changing travel behaviour in Japan. Transport policy, 13(5), 339-348.

Goodwin, P. (2012). Three views on peak car. World Transport Policy and Practice, 17(4).

Heath, Y., \& Gifford, R. (2002). Extending the Theory of Planned Behavior: Predicting the Use of Public Transportation1. Journal of Applied Social Psychology, 32(10), 2154-2189. doi: 10.1111/j.1559-1816.2002.tb02068.x.

Hunecke, M., Haustein, S., B hler, S., \& Grischkat, S. (2010). Attitude-based target groups to reduce the ecological impact of daily mobility behavior. Environment and Behavior, 42(1), 3-43.

Kline, R. B. (2011). Principles and practice of structural equation modeling: Guilford press.

Kuhnimhof, T., Armoogum, J., Buehler, R., Dargay, J., Denstadli, J. M., \& Yamamoto, T. (2012). Men shape a downward trend in car use among young adults - evidence from six industrialized countries. Transport Reviews, 32(6), 761-779.

Lai, W., \& Chen, C. (2011). Behavioral intentions of public transit passengers - The roles of service 
quality, perceived value, satisfaction and involvement. Transport Policy, 18(2), 318-325. doi: 10.1016/j.tranpol.2010.09.003.

Lu, X. (2010). Shanghai Fourth Comprehensive Traffic Survey Report: Shanghai Urban Construction and Communications Commission.

Matthies, E., Selge, S., \& Klöckner, C. A. (2012). The role of parental behaviour for the development of behaviour specific environmental norms-The example of recycling and re-use behaviour. Journal of Environmental Psychology, 32(3), 277-284.

Morikawa, T. (1989). Incorporating stated preference data in travel demand analysis (Doctoral dissertation, Massachusetts Institute of Technology).

Muthén, L. K., \& Muthén, B. O. (2010). Mplus User's Guide, from

https://www.statmodel.com/download/usersguide/Mplus\%20Users\%20Guide\%20v6.pdf, accessed December 20, 2013.

Nordlund, A. M., \& Garvill, J. (2003). Effects of values, problem awareness, and personal norm on willingness to reduce personal car use. Journal of Environmental Psychology, 23(4), 339-347. doi: 10.1016/S0272-4944(03)00037-9.

Peng, Z., Sun, J., \& Lu, Q. (2012). China's Public Transportation: Problems, Policies, and Prospective of Sustainability. ITE Journal, 82(5), 36-40.

Rosseel, Y. (2013). Package 'lavaan' reference manual, from http://cran.r-project.org/web/packages/lavaan/lavaan.pdf, accessed December 27, 2013. Schmitt, N. (1996). Uses and abuses of coefficient alpha. Psychological assessment, 8(4), 350.

Schwanen, T., Dijst, M., \& Dieleman, F. M. (2001). Leisure trips of senior citizens: determinants of modal choice. Tijdschrift voor economische en sociale geografie, 92(3), 347-360.

Schwartz, S. H. (1977). Normative Influences on Altruism. In B. Leonard (Ed.), Advances in Experimental Social Psychology (Volume 10, pp. 221-279): Academic Press.

Shanghai Municipal Transport and Port Authority (2013), Shanghai Metropolitan Transport White Paper, 2012.

Sheppard, M. E. (2011). Exploring Personal Values, Attitudes, Perceived Injunctive and Descriptive Norms, and Intrapersonal Value-attitude Relationships in Relation to Alcohol Use and Alcohol-related Problems Among College Students (Doctoral dissertation, The University of Alabama Tuscaloosa). Stopher, P. R. (2004). Reducing road congestion: a reality check. Transport Policy, 11(2), 117-131. Tan, X. (2013, 2014-02-20). To construct "Beautiful Hunan", almost 30\% people would like to drive less (in Chinese), from http://epaper.xxcb.cn/XXCBA/html/2013-02/01/content_2683794.htm, accessed December 12, 2013.

The Shanghai International Commodity Auction Co., Ltd. Results for Shanghai private car plate bid, April 2014, from http://www.alltobid.com/guopai/contents/56/2050.html, accessed April 28, 2014.

Thøgersen, J. (2006). Norms for environmentally responsible behaviour: An extended taxonomy. Journal of Environmental Psychology, 26(4), 247-261. doi: 10.1016/j.jenvp.2006.09.004.

Vaske, J. J. (2008). Survey research and analysis: Applications in parks, recreation and human dimensions: Venture Publishing State College, PA.

Walker, J. L. (2001). Extended discrete choice models: integrated framework, flexible error structures, and latent variables (Doctoral dissertation, Massachusetts Institute of Technology).

Wang, J., \& Ma, J. (2013). Shanghai Statistical Yearbook.

$\mathrm{Wu}$, R. (2011). Increase financial subsidy and promote public transport priority, from http://www.shcti.cn/cc/vxhhk.jsp?hkid=26\&zbtid=105, accessed December 27, 2013. 
Yáñez, M. F., Raveau, S., \& Ortúzar, J. D. D. (2010). Inclusion of latent variables in Mixed Logit models: Modelling and forecasting. Transportation Research Part A: Policy and Practice, 44(9), 744-753. doi: 10.1016/j.tra.2010.07.007.

Zhao, S., Dong, Z., \& Li, L. (2012). Study the influence of travel attitude on the travel behavior by transit December 26, 2013, from http://www.paper.edu.cn/download/downPaper/201212-584.

Zhu, C., Zhu, Y., Lu, R., He, R., \& Xia, Z. (2012). Perceptions and aspirations for car ownership among Chinese students attending two universities in the Yangtze Delta, China. Journal of Transport Geography, 24(0), 315-323. doi: 10.1016/j.jtrangeo.2012.03.011.

\section{Author Biographies}

Dong Zhang is a PhD student in the School of Traffic and Transportation Engineering at Tongji University, China. With support from CSC funding he spent one year at Kyoto University in 2012-2013. This paper is part of his doctoral research which investigates how physical and perceptual factors can encourage individuals to use public transport in Chinese cities.

Jan-Dirk Schmöcker is an Associate Professor in the Department of Urban Management, Kyoto University, Japan. Previously he held positions at Tokyo Institute of Technology and Imperial College London where he also obtained his PhD. His research interests cover public transport assignment as well as a range of travel behavioural issues. A recent focus has been on estimating and modelling the effects of social norms.

Satoshi Fujii is a Professor of Transportation and Behavior Science in the Department of Urban Management at Kyoto University and a Special Adviser for Public Policy to the Cabinet of Japan. He has been engaged in applied psychological research for behavioral modification of travel behavior. He is currently also the director of the "Resilience Research Unit" at Kyoto University.

Xiaoguang Yang is Professor in the School of Traffic and Transportation Engineering at Tongji University, China. His research interests focus on information augmented urban traffic system design and management. 